\title{
Perancangan Aplikasi Reservasi Tiket Bus Menggunakan Aztec Code Berbasis Andorid (Studi Kasus : Po. Bintang Prima)
}

\author{
Muhammad Rijal Pardi ${ }^{1}$, Risky Nurmala ${ }^{2}$ \\ ${ }^{1,2}$ Teknik Informatika, Sekolah Tinggi Manajemen Informatika dan Komputer Dipanegara, Makassar, Indonesia \\ E-mail: ${ }^{1}$ mrijal.pardi94@gmail.com, ${ }^{2}$ rezznurmala13@ rocketmail.com
}

\begin{abstract}
Abstrak
PO. Bintang Prima adalah perusahaan yang melayani jasa angkutan bus penumpang dimana bus ini melayani beberapa daerah disulawesi selatan. Namun proses pemesanan tiket yang ada pada

Kata Kunci saat ini yaitu dengan mendatangi loket pembelian tiket pada PO. Bintang Prima. Hal itu menyebabkan informasi detail tentang armada tidak diketahui langsung oleh penumpang. Oleh

Android; Aplikasi; Aztec code. karena itu, penulis membuat sebuah aplikasi pembelian tiket dengan memanfaatkan teknologi smartphone android sebagai media untuk memberikan informasi kepada calon penumpang, mengetahui jadwal keberangkatan serta mempermudah dalam pembelian tiket bus, padapengujian aplikasi ini menggunakan teknik pengujian black box. Diharapkan aplikasi ini nantinya dapat digunakan untuk melakukan pengecekan jadwal keberangkatan, harga tiket, dan pembelian tiket sesuai dengan nomer kursi yang diinginkan tanpa datang langsung ke PO. Bintang prima.
\end{abstract}

\begin{abstract}
PO. Bintang Primais a company that caters to the passenger bus transportation service where Keywords the bus serves several areas of South ssulawesi. However, the ticket booking process at this time

Android;

Application; Aztec code. is by visiting the ticket counter onPO. Bintang Prima. That caused detailed information about the fleet not known directly by the passenger. Therefore, the author plans to create a draft ticket purchase application by utilizing Android smartphone technology as a medium to provide information to the prospective passengers to know the departure schedule and facilitate the Bus ticket purchase, this app uses the black box test technique.. It is hoped that this application can be used to check the schedule of departures, ticket prices, and purchase tickets according to the desired seat number without coming directly to PO. Bintang Prima.
\end{abstract}

\section{PENDAHULUAN}

Perkembangan ilmu pengetahuan dan teknologi pada saat sekarang ini mempunyai peranan yang sangat penting, salah satunya di bidang computer (Nugraha, 2014). Terbukti dengan banyaknya lembaga/instansi pemerintah yang menggunakan sistem komputerisasi sebagai alat bantu untuk meningkatkan kreatifitas dan aktifitas para pegawai sehingga memiliki skill yang bagus dan menjadikan lembaga/instansi pemerintah memiliki kompetensi yang tinggi (Dani \& kariadi, 2018) (Suppa \& Saldi, 2018). Perkembangan teknologi informasi berkembang sangat pesat di era globalisasi saat ini teknologi informasi memegang peranan penting dalam memudahkan pekerjaan serta dapat meningkatkan kualitas (Apriyanto \& Berlian, 2018). Perusahaan Otobus (PO) Bintang Prima merupakan suatu perusahaan yang bergerak dibidang transportasi. Sebagai perusahaan yang profesional dibidangnya, PO. Bintang Prima senantiasa berusaha memberikan pelayanan yang cepat, mudah dan memuaskan costumernya. Selama ini dalam proses pembelian tiket perjalanan untuk transportasi bus pada PO. Bintang Prima masih secara konvensional yaitu para costumer (calon penumpang bus) datang langsung ke loket PO. Bintang Prima (Natsir 2016). Satu hal yang menjadi perhatian pihak manajemen PO. Bintang Prima adalah bagaimana cara yang ditempuh untuk memberikan pelayanan yang mudah bagi costumer dalam hal reservasi tiket perjalanan yang lebih mudah dan efesien.

Reservasi tiket bus pada PO. Bintang Prima kami menggunakan aztec code sebagai validasi tiket dan untuk mempermudah reservasi tiket dari makassar-palopo, makassar-masamba, dan makassar-toraja. Aztec code juga digunakan untuk mengetahui jika costumer sudah berada di bus yang di reservasinya.

Aztec code merupakan barcode 2D, aztec code banyak digunakan untuk tiket transportasi. Khususnya dalam proses pembelian tiket bus untuk menggantikan sistem penukaran tiket dengan konvensional yang memakan waktu lebih lama dan kurang efisien (Ara, 2016). Berdasarkan uraian tersebut 
maka akan dirancang sebuah "Aplikasi Reservasi Tiket Bus Menggunakan Aztec Code Berbasis Andorid (Studi Kasus : Po. Bintang Prima)" yang mempermudah masyarakat dalam pembelian tiket bus.

\section{METODELOGI PENELITIAN}

\subsection{Teknik Pengumpulan Data}

Pengumpulan data merupakan metode yang difungsikan untuk memperoleh informasi - informasi atau data - data terhadap kasus yang menjadi permasalahan dalam laporan tugas akhir ini (Hidayat dkk, 2016). Adapaun teknik pengumpulan data yang penulis lakukan berupa observasi, yaitu pengumpulan data dengan melakukan pengamatan secara langsung dan sistematis terhadap objek atau proses yang ada pada PO. Bintang Prima Makassar dan wawancara dengan bertanya langsung kepada pihak yang bersangkutan dalam hal ini kepala cabang PO. Bintang Prima yang berada dimakassar.

\subsection{Alat dan Bahan Penelitian}

a. Perangkat keras yang digunakan yaitu :

Tabel 3.1 Perangkat keras yang digunakan

\begin{tabular}{|c|c|c|c|}
\hline No. & Perangkat Keras & Unit & Spesifikasi \\
\hline 1. & Processor & 1 & Intel CORE i5 7th Gen \\
\hline 2. & Harddisk & 1 & $1 \mathrm{~Tb}$ \\
\hline 3. & RAM & 1 & $8 \mathrm{~Gb}$ \\
\hline 4. & Smartphone Android & 2 & Minimal Oreo \\
\hline
\end{tabular}

b. Perangkat lunak yang digunakan yaitu :

Tabel 3.2 Perangkat lunak yang digunakan

\begin{tabular}{|l|l|c|l|}
\hline No. & \multicolumn{1}{|c|}{ Perangkat Lunak } & Unit & \multicolumn{1}{|c|}{ Spesifikasi } \\
\hline 1. & Sistem operasi & 1 & windows 10, Android \\
\hline 2. & Bahasa Pemrograman & 1 & PHP, JSON, \& Android \\
\hline 3. & Database & 1 & MySQL, SQLite \\
\hline 4. & Editor & 1 & Android Studio, Sublime Teks \\
\hline
\end{tabular}

Tabel 3.3 Bahan Penelitian

\begin{tabular}{|c|l|}
\hline No. & \multicolumn{1}{|c|}{ Bahan penelitian } \\
\hline 1. & Data bus PO. Bintang Prima Makassar. \\
\hline 2. & Data tujuan keberangkatan. \\
\hline 3. & Jadwal keberangkatan. \\
\hline 4. & Tarif \\
\hline
\end{tabular}

\section{PEMBAHASAN DAN DISKUSI}

\subsection{Analisis Sistem}

Pada aplikasi ini terdiri dari dua system yaitu, Administrator dan costumer. Pada administrator berfungsi untuk menginput data-data berupa data managemen bus, managemen jadwal,costumer, transaksi dan data yang diolah admin sedangkan pada costumer digunakan bagi reservasi tiket perjalanan dan melakukan transaksi (pembayaran). Adapun Kernet berfungsi untuk scan aztec code pada costumer yang telah mempunyai e-tiket.

\subsection{Perancangan Sistem Use Case Diagram}

Use case diagram merupakan sebuah teknik yang digunakan dalam pengembangan sebuah software atau sistem informasi untuk menangkap kebutuhan fungsional dari sistem yang bersangkutan, use case diagram menjelaskan interaksi yang terjadi antara 'aktor' inisiator dari interaksi sistem itu sendiri dengan sistem yang ada, sebuah use case diagram direpresentasikan dengan urutan langkah yang sederhana.

Perilaku sistem adalah bagaimana sistem beraksi dan bereaksi. Perilaku ini merupakan aktifitas sistem yang bisa dilihat dari luar dan bisa diuji. Perilaku sistem ini dicapture di dalam use case diagram. Use case diagram sendiri mendeskripsikan sistem, lingkungan sistem, serta hubungan antara sistem dengan lingkungannya 


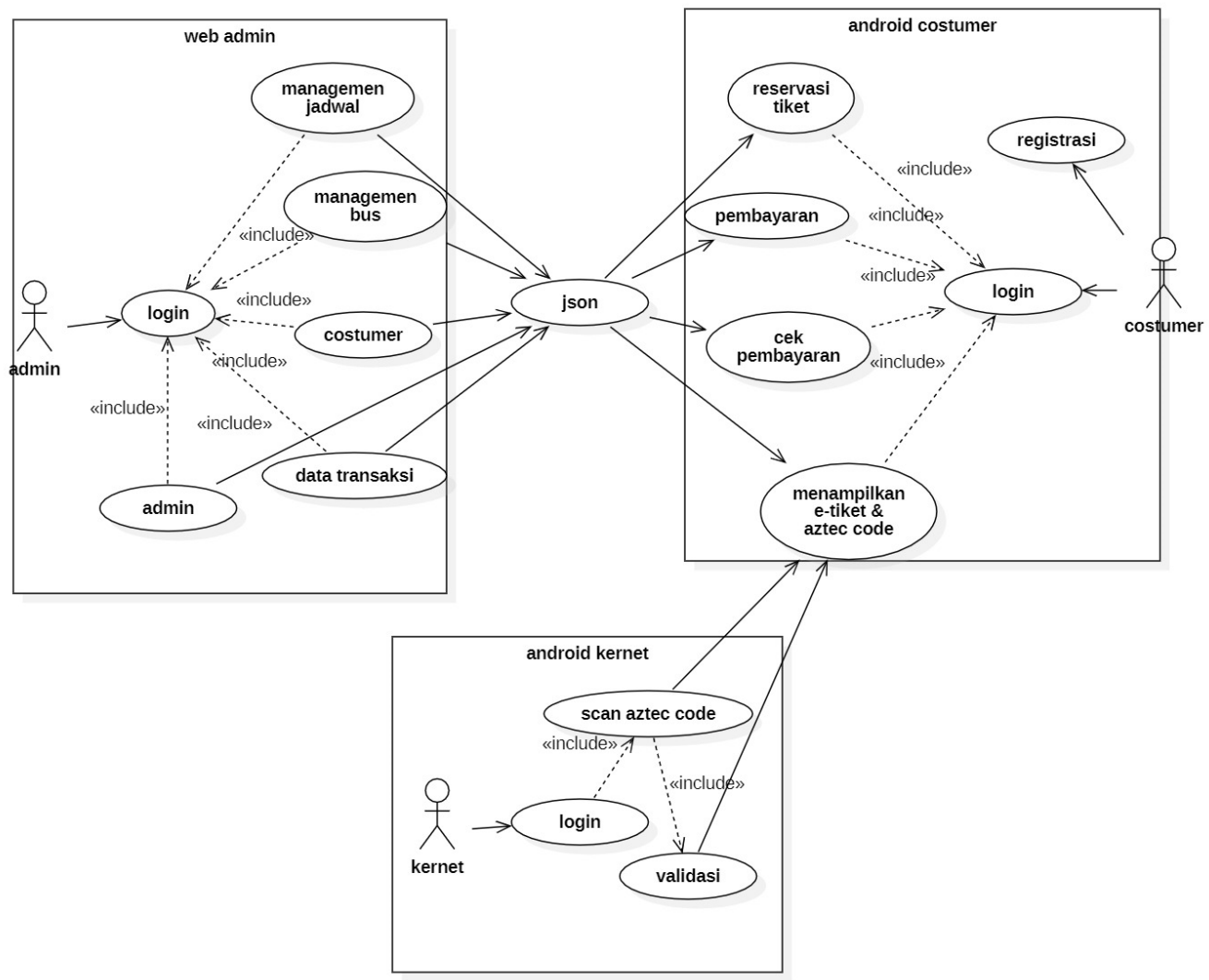

Gambar 1 Use Case Diagram Aplikasi

Pada gambar 4.1 use case diagram aplikasi yang akan dibuat terdiri dari 3 aktor yaitu actor admin, aktor costumer dan actor kernet. Aktor yang pertama yaitu admin disinibertugas untuk manajemen admin, tambah data bus , tambah jalur bus, tambah jadwal bus, melihat bus yang sedang dalam perjalanan, menerbitkan etiket dan aztec code, memverifikasi pembayaran costumer dan melakukan pemesanan tiket bagi customer yang membeli tiket tidak melalui aplikasi. Aktor yang kedua yaitu costumer berfungsi untuk memesan tiket, menentukan kelas bus, tujuan bus, melakukan pembayaran. Aktor yang ketiga yaitu kernet bertugas untuk menscan aztec code dan konfirmasi ke admin jika bus sudah berangkat dan tiba ditujuan.

\subsection{Struktur Basis Data}

Adapun rancangan tabel yang digunakan pada penelitian ini adalah sebagai berikut :

1. Tabel Bus

Tabel 4.1 Tabel Bus

\begin{tabular}{|c|l|l|c|}
\hline No & \multicolumn{1}{|c|}{ Nama Field } & \multicolumn{1}{c|}{ Type } & Ukuran \\
\hline 1 & Id & Bigint & 20 \\
\hline 2 & Nama & Varchar & 255 \\
\hline 3 & Id_tipebus & Bigint & 20 \\
\hline 4 & Deskripsi & Varchar & 255 \\
\hline 5 & Jumlah_kursi & Int & 11 \\
\hline
\end{tabular}

2. Jadwal Bus

Tabel 4.2 Jadwal Bus

\begin{tabular}{|c|l|l|c|}
\hline No & \multicolumn{1}{|c|}{ Nama Field } & \multicolumn{1}{c|}{ Type } & Ukuran \\
\hline 1 & Id & Bigint & 20 \\
\hline 2 & Id_bus_rute & Bigint & 20 \\
\hline 3 & Tanggal & Date & - \\
\hline 4 & Jam & Varchar & 255 \\
\hline 5 & Status & enum & - \\
\hline
\end{tabular}


3. Tabel Kursi

Tabel 4.3 Kursi

\begin{tabular}{|c|l|l|c|}
\hline No & \multicolumn{1}{|c|}{ Nama Field } & \multicolumn{1}{c|}{ Type } & Ukuran \\
\hline 1 & Id jadwal & Bigint & 20 \\
\hline 2 & Kursi & Varchar & 255 \\
\hline 3 & Status & enum & - \\
\hline
\end{tabular}

4. Tabel Rute

Tabel 4.4 Rute

\begin{tabular}{|c|l|l|c|}
\hline No & \multicolumn{1}{|c|}{ Nama Field } & \multicolumn{1}{c|}{ Type } & Ukuran \\
\hline 1 & Id & Bigint & 20 \\
\hline 2 & Rute & Varchar & 255 \\
\hline
\end{tabular}

5. Tabel Pivot_Bus_Rute

Tabel 4.5 Pivot_Bus_Rute

\begin{tabular}{|c|l|l|c|}
\hline No & \multicolumn{1}{|c|}{ Nama Field } & \multicolumn{1}{|c|}{ Type } & Ukuran \\
\hline 1 & Id & Bigint & 20 \\
\hline 2 & Id_bus & bigint & 20 \\
\hline 3 & Id_rute & Bigint & 20 \\
\hline 4 & Harga & Int & 11 \\
\hline
\end{tabular}

6. Tabel Tipe Bus

Tabel 4.6 Tipe Bus

\begin{tabular}{|l|l|l|c|}
\hline No & \multicolumn{1}{|c|}{ Nama Field } & \multicolumn{1}{c|}{ Type } & Ukuran \\
\hline 1 & Id & Bigint & 20 \\
\hline 2 & Nama & Varchar & 255 \\
\hline
\end{tabular}

7. Tabel Transaksi

Tabel 4.7 Transaksi

\begin{tabular}{|l|l|l|c|}
\hline No & \multicolumn{1}{|c|}{ Nama Field } & \multicolumn{1}{c|}{ Type } & Ukuran \\
\hline 1 & Id & Bigint & 20 \\
\hline 2 & Order_code & Varchar & 255 \\
\hline 3 & Id_jadwal & Bigint & 20 \\
\hline 4 & Id_costumer & Bigint & 20 \\
\hline 5 & Status_bayar & Enum & - \\
\hline 6 & No_kursi & Varchar & 255 \\
\hline 7 & Aztec code & Varchar & 255 \\
\hline 8 & Trip & Enum & - \\
\hline 9 & Bukti transfer & varchar & 255 \\
\hline
\end{tabular}

8. Tabel user

Tabel 4.8 User

\begin{tabular}{|l|l|l|c|}
\hline No & \multicolumn{1}{|c|}{ Nama Field } & \multicolumn{1}{c|}{ Type } & Ukuran \\
\hline 1 & Id & Bigint & 20 \\
\hline 2 & Nama & Varchar & 255 \\
\hline 3 & Email & Varchar & 255 \\
\hline 4 & Role & Enum & - \\
\hline 5 & Password & Varchar & 255 \\
\hline 6 & Alamat & Varchar & 255 \\
\hline
\end{tabular}


Perancangan Aplikasi Reservasi Tiket Bus Menggunakan Aztec Code Berbasis Andorid (Studi Kasus : Po. Bintang Prima) Muhammad Rijal Pardi, Risky Nurmala

\section{Skenario Sistem}

\section{Admin Web}

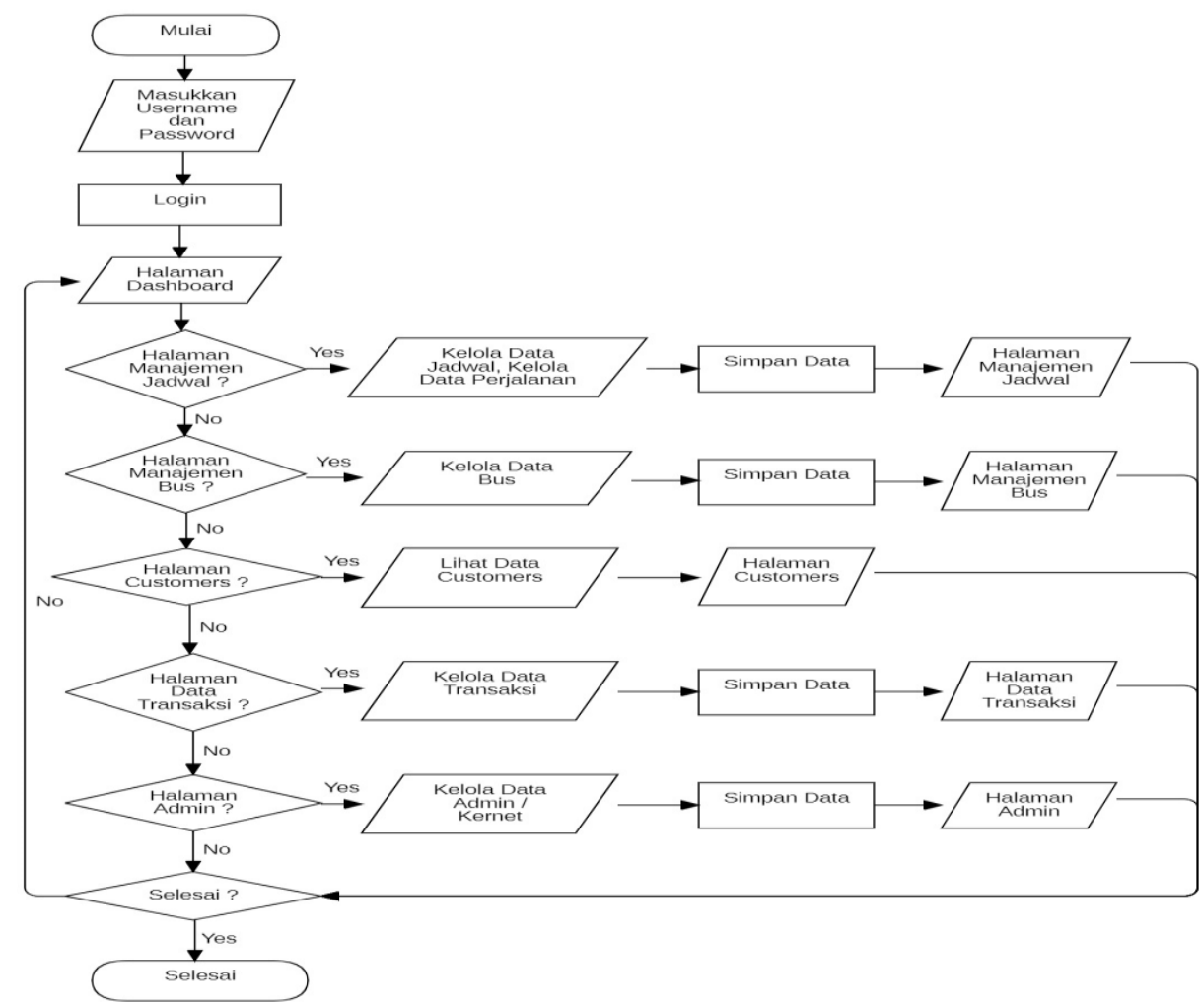

Gambar 4.44 Admin Web

\section{Costumer android}

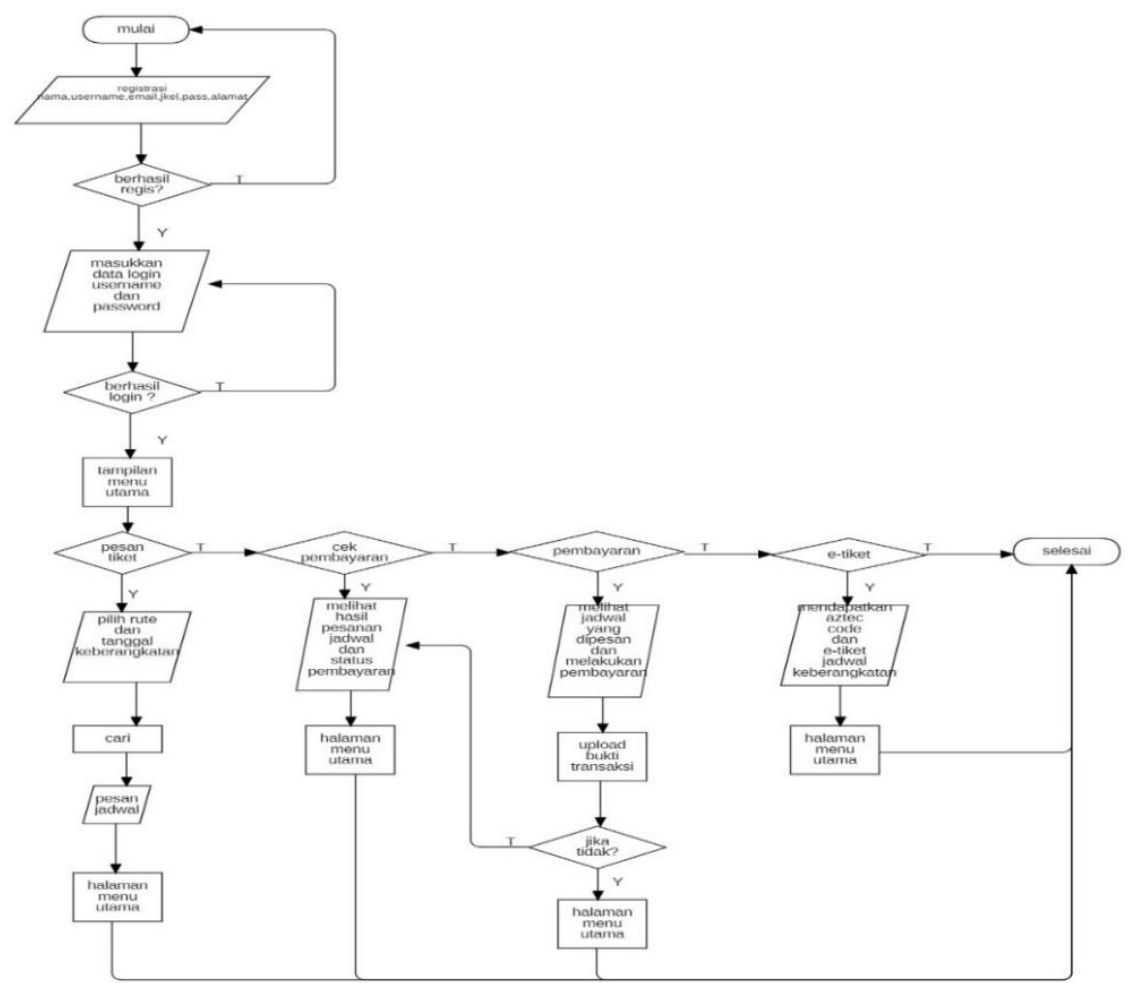




\section{Kernet android}

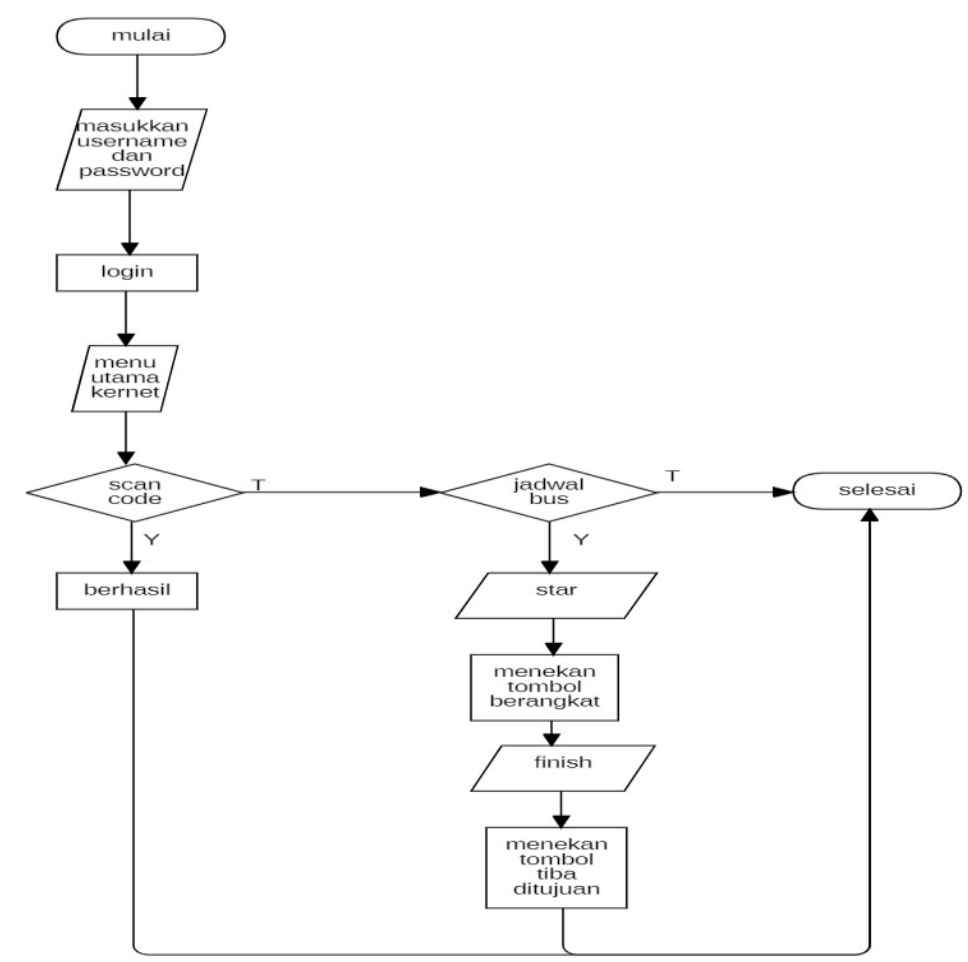

\section{PENUTUP}

\subsection{Kesimpulan}

Setelah melalui tahap perancangan, implementasi, pengujian, dan analisa maka dapat diambil beberapa kesimpulan yaitu dengan adanya rancangan aplikasi reservasi tiket bus, makapara costumer dapat lebih mudah untuk melakukan pemesanan tiket bus pada PO. Bintang Prima secara online. Rancangan aplikasi ini memberikan fasilitas pemilihan tujuan dan waktu keberangkatan sesuai dengan kebutuhan costumer. Secara interaktif calon penumpang juga melihat kursi yang tersedia sehingga dapat lebih mudah dalam menentukan tempat duduk sesuai dengan yang diinginkan. Dengan adanya rancangan aplikasi reservasi pemesanan tiket bus pada PO. Bintang Prima, maka costumer dipermudah dalam pembayaran tiket bus, karena pembayaran tidak perlu datang langsung ke loket tetapi bisa secara online.

\subsection{Saran}

Agar memperoleh hasil yang lebih baik kedepannya untuk pembelian tiket bus secara online maka penulis memberikan saran yakni pengembangan lebih lanjut menggunakan aztec code sebagai sistem validasi dalam reservasi Tiket Bus berbasis android serta tampilan pada rancangan aplikasi reservasi tiket bus agar lebih menarik serta dapat menarik lebih banyak costumer.

\section{DAFTAR PUSTAKA}

Apriyanto. Berlian (2018). Sistem Informasi Perpustakaan Berbasis Web pada Fakultas Teknik Universitas Andi Djemma Palopo. PENA TEKNIK: Jurnal Ilmiah Ilmu-ilmu Teknik 3(2), 157 - 168

Ara, Rahmat, (2016). "Aplikasi Pemesanan Tiket Bus Berbasis Web (Studi Kasus Pada Po.Harapan Jaya)", Jurnal Informatika Universitas Pamulang Vol.1, No.1,

Dani AAH, Kariadi FF (2018). Sistem Informasi Penggajian (Studi Kasus: kantor Ratona Televisi Palopo). PENA TEKNIK: Jurnal Ilmiah Ilmu-ilmu Teknik 3(3), 147 - 156

Hidayat, Wahyu, Anita B. Wandayana, Recha Fadriansyah. 2016. "Perancangan Video Profile Sebagai Media Promosi Dan Informasi Di Smk Avicena Rajeg Tangerang". Jurnal Cerita Vol. 2 No. 1 Februari 2016. 
Natsir, Rakhmawati (2016). Karakteristik Kinerja Moda Angkutan Umum Kota Palopo (Studi Kasus Penumpang Bus Executive, Suspensi udara, Scania-PU Bintang Prima). PENA TEKNIK: Jurnal Ilmiah Ilmu-ilmu Teknik 1(2), 156 - 162

Nugraha, F. (2014). Analisa dan Perancangan Sistem Informasi Perpustakaan. Jurnal SIMETRIS, 5(1), 27-32.

Suppa, R. Saldi T. (2018). Sistem Informasi Indekos Berbasis Web. PENA TEKNIK: Jurnal Ilmiah Ilmuilmu Teknik 3(2), 139 - 146 